\title{
Assessing Interdependence Among Countries' Fundamentals and its Implications for Exchange Rate Misalignment Estimates: An Empirical Exercise Based on GVAR ${ }^{\star}$
}

\author{
Emerson Fernandes Marçal ${ }^{\dagger}$ Beatrice Zimmermann; \\ Diogo de Prince, Giovanni Merlin
}

\section{Contents}

1. Introduction.....

2. A short review of exchange rate misalignment

literature

3. Methodologies to calculate exchange rate

misalignment....

4. Results

5. Final remarks

\section{Keywords}

Real effective exchange rate, cointegration, global VAR

JEL Codes

C52, F31, F37

\begin{abstract}
Resumo
Exchange rates are important macroeconomic prices and changes in these rates affect economic activity, prices, interest rates, and trade flows. Methodologies have been developed in empirical exchange rate misalignment studies to evaluate whether a real effective exchange is overvalued or undervalued. There is a vast body of literature on the determinants of long-term real exchange rates and on empirical strategies to implement the equilibrium norms obtained from theoretical models. This study seeks to contribute to this literature by showing that the global vector autoregressions model (GVAR) proposed by Pesaran, Schuermann, and Weiner (2004) can add relevant information to the literature on measuring exchange rate misalignment. Our empirical exercise suggests that the estimate exchange rate misalignment obtained from GVAR can be quite different to that using the traditional cointegrated time series techniques, which treat countries as detached entities. The differences between the two approaches are more pronounced for small and developing countries. Our results also suggest a strong interdependence among eurozone countries, as expected.
\end{abstract}

\section{Introduction}

The exchange rate is an important macroeconomic price and changes in these rates affect economic activity, prices, interest rates, and trade flows. Large changes in an exchange rate always generate debate on whether the movements are "excessive", reflect "fundamentals", or are "rational". Empirical studies have developed models to assess the long-term determinants of real exchange rates. Empirical strategies are then formulated based on these models, using the doctrine of purchasing power parity (PPP), or based on a fundamentals analysis.

\footnotetext{
*The authors acknowledge the comments from the participants of the first International Annual Applied Econometric Conference, fourth Emerging Market Group Conference, fourteenth OxMetrics User Conference. The authors also acknowledge Joseph Gagnon, Luis Catão, Irineu Evangelista, Pedro Valls, Megumi Kubota, Cesar Calderon, Aluisio de Lima Campos and Vera Thorstensen for helpful comments on a very preliminary version of this work. All remaining errors are the responsibility of the authors.

${ }^{\dagger}$ Fundação Getulio Vargas, Escola de Economia de São Paulo, Centro de Macroeconomia Aplicada (FGV/EESP/CEMAP). Rua Itapeva 286, $10^{\circ}$ andar, São Paulo, SP, CEP 01332-000, Brasil. This author acknowledges partial financial support received from CNPQ (Grant number 311044/2013-1) and from WTO Chair Project.

‡World Bank, DIME. Setor Comercial Norte, Quadra 2, Lote A, Edifício Corporate Financial Center, $7^{\circ}$ andar, Brasília, DF, CEP 70712-900, Brasil.

${ }^{\S}$ Universidade Federal de São Paulo, Escola Paulista de Política, Economia e Negócios (Unifesp/EPPEN). Address: Rua Angélica, 100, Jd. das flores, Osasco, SP, 06110-295, Brazil.

'PhD in Economics at Escola de Economia de São Paulo. Dorfstrasse 9, 8800, Thalwil, Switzerland.

$\square$ emerson.marcal@fgv.br $\square$ beatrice_aline@hotmail.com $\square$ dioted@gmail.com $\square$ giovanni.merlin@fgv.br
} 
Many studies have attempted to construct more accurate estimates of the magnitude and sign of exchange rate misalignment. Exchange rate misalignment is defined as the difference between a measure of the real exchange rate and some equilibrium norm. Discussions on exchange rate misalignment can be divided into two levels. The first focuses on which is the best norm to use to evaluate exchange rate equilibrium. Economic models give a better understanding of the determinants of the real exchange rate. These models attempt to determine the best set of fundamentals that explain real effective exchange rates in the long run. The second level of debate revolves around the best empirical strategy to measure exchange rate equilibrium norms. This is an econometric debate.

Empirical studies also need to choose between a time series or panel approach. The time series approach has the advantage of allowing a particular structure to be estimated for each country. However, the approach does not allow a broader set of variables to be analyzed at the same time because the available macroeconomic samples are not long enough. Panel techniques allow analysts to enlarge the spectrum of variables, but at the cost of imposing untested similarities between the parameters of different countries' models. Hossfeld (2010) reviews exchange rate misalignment literature, and evaluates the benefits and limits of the time series and panel approaches.

This study seeks to contribute to the current body of literature by showing that the global vector autoregressions model (GVAR) proposed by Pesaran, Schuermann, and Weiner (2004) can be used to model the interdependence between countries. In addition, the model can add relevant information to the literature on measuring exchange rate misalignment. As far as the authors are aware, this approach has not been applied to exchange rate misalignment estimation.

This paper is divided into five sections. The first is this introduction. Section 2 provides a brief review of current literature on exchange rate misalignment determinants and describes the challenges faced by empirical studies in trying to determine whether a country's exchange rate is overvalued or undervalued. Section 3 presents the global vector autoregressive model and explains how to adapt Gonzalo and Granger's methodology to this framework. Section 4 describes the results of an empirical exercise that models real effective exchange rates for a selected group of countries. Here, we also present a comparative analysis of the traditional time series approach and the GVAR approach to exchange rate misalignment. Our results suggest that the GVAR approach is worth considering. section 5 applies the limits and the merits of the GVAR approach to the exchange rate misalignment problem and suggests possible extensions to our work. This section also concludes the paper.

\section{A short review of exchange rate misalignment literature}

The literature on real exchange rates is extensive (Froot \& Rogoff, 1995). The classical doctrine, and perhaps the oldest one on real exchange rate determinants is that of purchasing power parity (PPP). Reference to this theory can be found in classic studies. Recent studies confirm the validity of PPP for tradable goods, although the adjustment towards equilibrium is quite slow. Ahmad and Craighead (2011) obtained strong evidence of a mean reversion with a high half-life using a secular consumer price index dataset for the United States and United Kingdom. Their work investigates the point made by Taylor (2001) on the effects of temporal aggregation on PPP tests.

There is also much theoretical discussion on which variables drive the real exchange rate in the long term. Older studies include those of Edwards $(1989,1991)$, who analyzes 
the causes and consequences of exchange rate misalignment, and Dornbusch (1976), who developed the classic flexible exchange rate model approach under which monetary policy shocks cause deviations from PPP fundamentals.

The studies of Bilson (1979) and Mussa (1976) are also classics. These are key references for the monetary approach to exchange rates. Under this approach, the exchange rate would be primarily driven by two fundamentals: the difference between domestic and foreign income, and the money supply. The approach assumes that PPP and uncovered interest parity (UIP) hold continuously, and that the demand for money is stable in all countries. However, the research by Meese and Rogoff (1983) casts doubt on the explanatory power of this theory by showing that the predictions of this approach are not superior to a "naive" forecast model for exchange rates, such as a pure random walk. Rossi (2013) shows that the random walk can be outperformed by an econometric model that uses information based on net foreign investment position. "Predictability is most apparent when one or more of the following hold: the predictors are Taylor rule and net foreign assets fundamentals; the model is linear; and a small number of parameters are estimated" Rossi (2013).

Stein (1995) formulated the natural exchange rate approach (NATREX). According to the author, the equilibrium exchange rate is one that is equal to the level of investment and savings generated by economic fundamentals.

Williamson (1994) had a significant impact on exchange rate misalignment theory. Here, the equilibrium exchange rate is the one that allows a country to sustain a desirable result in its external accounts. This is referred to as the fundamental real exchange rate approach (FRER). A more recent reference to this approach is that of Cline and Williamson (2008). A limitation of this approach is that choosing the target of foreign accounts is highly arbitrary and subjective. As a result, the results may not be robust to different targets. In addition, this approach focuses on flows, not stocks.

Faruqee (1995) incorporates the evolution of stocks and constructed a model that allows flows and stocks to interact. Thus, there must be a stable relationship between the real exchange rate and the net foreign asset position between residents and non-residents. This is referred to as the behavioral real exchange rate (BRER) approach. The model was subsequently extended by Alberola, Cervero, Lopez, and Ubide (1999).

Kubota (2009) includes a representative agent who maximizes intertemporal consumption and accumulates capital. This study indicates that the real exchange rate is a function of terms of trade, net external position, and the relative productivity of the tradable and nontradable sectors. This approach seeks to reduce the degree of subjectivity when estimating exchange rate misalignment. To this end, she establishes a link between the real exchange rate and a set of fundamentals derived from a theoretical model. She then decomposes the series of real exchange rates into transitory and permanent components using the time series econometric technique.

Recently, the International Monetary Fund (IMF) began to systematically disseminate its research efforts into measuring the exchange rate misalignment in several of its member countries (IMF, 2013). Two documents were recently released. These works are an important advance towards transparency. The codes and dataset used to calculate the exchange rate misalignment are available on the IMF website, and the results are easy to replicate. The methodology is also a step forward in incorporating the role of policy gaps in exchange rate misalignment estimates.

The External Balance Assessment (EBA) methodology, developed by the IMF's research department, is based on two panel estimations: one for the current account and one for the 
real effective exchange rate (REER) indices. ${ }^{1}$ The basic idea is that the REER can be written as a function of the output gap, real interest rate differential, and factors that may affect saving, investment, current account, capital flows, and changes in foreign currency reserves.

The explanatory variables included in the EBA model are the commodity terms of trade, trade openness, share of administered prices, VIX, ${ }^{2}$ the share of own currency in world reserves, financial home bias, population growth, expected GDP growth over the next five years, productivity, and changes in foreign reserves. The following policy-related regressors are also included: health expenditure to GDP, foreign exchange interventions, real short-term interest rate differential, private credit to GDP, and capital controls. Most of the variables described are relative to the country's trade partners. They use the same weights as the REER calculation and/or interact with capital account openness. In addition, some variables are lagged to control for endogeneity. The sample data covers 40 countries over the period 1990-2010. The model includes countries fixed effects. To guarantee multilateral consistency in the results, the exchange rate misalignment must be adjusted.

Given the results of the estimation, the "Total REER Gap" can be calculated as the sum of the regression residual and the "Total Policy Gap". The policy gap is a measure of a cyclical gap (over a benchmark) in six policy areas: fiscal balance, capital controls, social spending, foreign exchange market intervention, financial policies, and monetary policy. The gap is calculated as the difference between the actual level of the variable and its "desirable" level, multiplied by the value of the estimated coefficient. The "desirable" levels are supplied by the desk of each IMF country.

\section{Methodologies to calculate exchange rate misalignment}

\subsection{Traditional time series approach}

The analysis starts with an estimation of a vector error correction model (VECM), as suggested by Johansen $(1988,1995)$. The model is given by equation (1):

$$
\Delta x_{i t}=\alpha_{i} \beta_{i}^{\prime} x_{i, t-1}+\Gamma_{i 1} \Delta x_{i, t-1}+\cdots+\Gamma_{i, k-1} \Delta x_{i, t-k+1}+\Phi_{i} D_{t}+\varepsilon_{i t},
$$

where $\varepsilon_{i t}$ are not correlated random errors. The vector $x_{i t}$ contains the variables for the real exchange rate and the fundamentals (e.g., net foreign investment position, etc.) and has dimension $p$; $D_{t}$ contains deterministic terms; and $\theta=\left\{\alpha_{i}, \beta_{i}, \Gamma_{i 1}, \ldots, \Gamma_{i, k-1}, \Phi_{i}\right\}$ is the set of parameters to be estimated.

\section{The Gonzalo and Granger decomposition}

Several decompositions have been proposed to decompose the series into transitory and permanent components. The decomposition of Gonzalo and Granger (1995) is widely used in exchange rate misalignment empirical literature. ${ }^{3}$ In their decomposition, the transitory components do not cause changes in the permanent component in the long term. In other words, exchange rate misalignment - defined as the transitory component of the real exchange rate in a multivariate equation system - does not contain relevant information for predicting the changes of the permanent components in the long term.

\footnotetext{
${ }^{1} \mathrm{~A}$ full description of the methodology, data, and routines are available at http://www.imf.org/external/np/spr/ 2013/esr/

${ }^{2}$ Chicago Board Options Exchange Market Volatility Index.

${ }^{3}$ For example, Alberola et al. (1999) and Kubota (2009).
} 
Using the parameters from (1), it is possible to calculate the transitory component $\left(T_{i t}\right)$ and the permanent component $\left(P_{i t}\right)$ from the following equations:

$$
\begin{aligned}
& P_{i t}=\beta_{i}\left(\alpha_{i \perp}^{\prime} \beta_{i \perp}\right)^{-1} \alpha_{i \perp}^{\prime} x_{i t}, \\
& T_{i t}=\alpha_{i}\left(\beta_{i}^{\prime} \alpha_{i}\right)^{-1} \beta_{i}^{\prime} x_{i t} .
\end{aligned}
$$

The estimate of exchange rate misalignment is the component associated with the position of the real exchange rate in vector $x_{i t}$. Assuming that the real exchange rate is in the first position of the vector, and using the value of the error correction mechanism centered on their own means, one can calculate the misalignment using the following equation:

$$
m i s_{i t} \equiv\left[\begin{array}{llll}
1 & 0 & \cdots & 0
\end{array}\right] \alpha_{i}\left(\beta_{i}^{\prime} \alpha_{i}\right)^{-1}\left(\beta_{i}^{\prime} x_{i t}-\mathbb{E}\left[\beta_{i}^{\prime} x_{i t}\right]\right) \text {. }
$$

\subsection{Motivation for a global model}

The severity of the U.S. economic crisis in 2008 brought the fear of a strong negative contagion to the rest of the world. The U.S. authorities have subsequently adopted an aggressive monetary policy with a strong reduction in nominal interest rates and monetary expansion, among other measures. Some analysts may argue that this policy could have generated strong pressure to depreciate the U.S. dollar against currencies whose domestic interest rates did not follow the same movement. Countries that did not follow such a reduction and opted to accumulate reserves to prevent the appreciation of their currency could have faced inflationary pressures. Some authors argue that the United States was using its monetary policy to depreciate its currency, thereby fostering aggregate demand to reduce the intensity and duration of the economic slowdown. This policy may have generated repercussions around the world. There is much discussion about the extension of these effects and whether they are deleterious.

We construct a global model to assess the magnitude of effects, similar to those discussed in the previous paragraph. In this context, the GVAR appears to be an interesting option, as the relevance and magnitude of global factors, vis-a-vis domestic components, can be explicitly and properly evaluated and tested.

\subsubsection{GVAR model}

In this study, we apply the GVAR methodology to ascertain whether there is any external factor affecting the real exchange rate in the long or short run for a group of selected countries. In this sense, the measure of exchange rate misalignment may have two components. The first is related to domestic fundamentals and the second to global factors. The GVAR explains the source of external influences on the domestic economy by including external variables in VARX. ${ }^{4}$ External variables are usually assumed to be weakly exogenous for each country, as defined in Engle, Hendry, and Richard (1983) and Hendry (1995).

In general, the GVAR can be described as a two-step approach. In the first step, a specific model for each country is estimated using the variables of the country and the trading partners weighted average of external variables. Then, all individual models are stacked and grouped into a system of equations, which are solved. Once this is done, the model provides options for different types of analyses, such as the forecast evaluation and impulse response

\footnotetext{
${ }^{4}$ VARX is the vector autoregression (VAR) model that contains exogenous variables.
} 
analysis. Overall, there is a set of individual models represented as VARX that are combined to obtain the GVAR.

Following the notation of Pesaran et al. (2004), we restrict our discussion to the specification with first-order dynamics, as represented by $\operatorname{VAR}(1,1)$. We consider a set of $N$ countries and the $\operatorname{VAR}(1,1)$ below:

$$
x_{i t}=a_{i, 0}+a_{i, 1} t+\Phi_{i} x_{i, t-1}+\Lambda_{i, 0} x_{i, t}^{*}+\Lambda_{i, 1} x_{i, t-1}^{*}+\varepsilon_{i t},
$$

where $x_{i t}$ is a vector of $k_{i} \times 1$ specific variables for each country; $x_{i, t}^{*}$ is a vector of $k_{i}^{*} \times 1$ foreign variables, $i=1,2, \ldots, N, t=1,2, \ldots, T ; \Lambda_{i, 0}$ and $\Lambda_{i, 1}$ are respectively matrices with parameters of the contemporaneous and lagged terms; $a_{i, 0}$ is a vector containing the constant; and $a_{i, 1}$ is the coefficient associated with the time trend. The term $\varepsilon_{i t}$ is a vector of idiosyncratic shocks for each country.

We construct the external variables using the trade weights, $w$,

$$
x_{i t}^{*}=\sum_{j=1}^{N} w_{i, j} x_{j t}
$$

where $\sum_{j=1}^{N} w_{i j}=1$ with $j=1, \ldots, N$ and $w_{i i}=0$ with $i=1, \ldots, N$. From (5), we can see that the domestic variable, $x_{i t}$, depends on the external variable $x_{i t}^{*}$. The system from equation (5) needs to be solved for all domestic variables.

We can obtain the global VAR defining $z_{i t}=\left(\begin{array}{l}x_{i t} \\ x_{i t}^{*}\end{array}\right)$ and we rewrite (5) as

$$
A_{i} z_{i t}=a_{i 0}+a_{i 1} t+B_{i} z_{i, t-1}+\varepsilon_{i t},
$$

where $A_{i}=\left(I_{k i},-\Lambda_{i 0}\right)$, and $B_{i}=\left(\Phi_{i}, \Lambda_{i 1}\right)$. The terms $A_{i}$ and $B_{i}$ have dimension $k_{i} \times\left(k_{i}+k_{i}^{*}\right)$, and $A_{i}$ has full column rank, $k_{i}$.

We can define the external variables as

$$
z_{i t}=W_{i} z_{t},
$$

where $W_{i}$ is a weight matrix with dimension $\left(k_{i}+k_{i}^{*}\right) \times k$, where $k=\sum_{i=1}^{N} k_{i}$. The matrix $W_{i}$ reflects the relationship between countries and allows us to unify the model into a complete global model. Using (8) and (7), we obtain

$$
A_{i} W_{i} z_{t}=a_{i 0}+a_{i 1} t+B_{i} W_{i} z_{t-1}+\varepsilon_{i t},
$$

where $A_{i} W_{i}$ and $B_{i} W_{i}$ have dimension $k_{i} \times k$. Finally, the stacked equations can be written as a $\operatorname{GVAR}(1)$ :

$$
G z_{t}=a_{0}+a_{1} t+H z_{t-1}+\varepsilon_{t},
$$

where $a_{o}=\left[\begin{array}{c}a_{10} \\ a_{20} \\ \vdots \\ a_{N 0}\end{array}\right], a_{1}=\left[\begin{array}{c}a_{11} \\ a_{21} \\ \vdots \\ a_{N 1}\end{array}\right], \varepsilon_{t}=\left[\begin{array}{c}\varepsilon_{1 t} \\ \varepsilon_{2 t} \\ \vdots \\ \varepsilon_{N t}\end{array}\right], \boldsymbol{G}=\left[\begin{array}{c}A_{1} W_{1} \\ A_{2} W_{2} \\ \vdots \\ A_{N} W_{N}\end{array}\right], \boldsymbol{H}=\left[\begin{array}{c}B_{1} W_{1} \\ B_{2} W_{2} \\ \vdots \\ B_{N} W_{N}\end{array}\right]$.

Assuming that $G$ is not singular and has dimension $k \times k$, the reduced form of (10) can be rewritten as:

$$
z_{t}=b_{0}+b_{1} t+F z_{t-1}+v_{t},
$$

where $F=G^{-1} H, b_{0}=G^{-1} a_{0}, b_{1}=G^{-1} a_{1}$ and $v_{t}=G^{-1} \varepsilon_{t}$.

After estimating the models for each country separately from (5), we can solve the global model in (11) to obtain recursively the future values of all endogenous variables $\left(z_{t}\right)$. 


\subsubsection{The GVAR and Gonzalo and Granger decomposition}

For the remainder of the paper, we will rewrite the GVAR as the global vector error correction model (GVECM). Both are equivalent, but the GVECM allows us to deal with permanent and transitory decompositions.

Assuming the following GVECM and stacking the models, we obtain that

$$
\Delta X_{t}=A B^{\prime} Z_{t-1}+\tilde{\Gamma}_{1} \Delta Z_{t-1}+\cdots+\tilde{\Gamma}_{k-1} \Delta Z_{t-k+1}+\tilde{\Phi} D_{t}+\tilde{\Gamma}_{0,1} \Delta \bar{X}_{t}+\tilde{\varepsilon}_{t},
$$

where

$$
A=\left[\begin{array}{ccccc}
\tilde{\alpha}_{1} & 0 & \cdots & 0 & 0 \\
0 & \tilde{\alpha}_{2} & \cdots & 0 & 0 \\
\vdots & \vdots & \ddots & \vdots & \vdots \\
0 & 0 & \cdots & \tilde{\alpha}_{N-1} & 0 \\
0 & 0 & \cdots & 0 & \tilde{\alpha}_{N}
\end{array}\right] ; \quad \boldsymbol{B}=\left[\begin{array}{ccccc}
\tilde{\beta}_{1} & 0 & \cdots & 0 & 0 \\
0 & \tilde{\beta}_{2} & \cdots & 0 & 0 \\
\vdots & \vdots & \ddots & \vdots & \vdots \\
0 & 0 & \cdots & \tilde{\beta}_{N-1} & 0 \\
0 & 0 & \cdots & 0 & \tilde{\beta_{N}}
\end{array}\right] ;
$$

$\tilde{\varepsilon}_{t}$ are random errors, not time correlated;

$$
\begin{aligned}
& X_{t}^{\prime}=\left[\begin{array}{lllll}
X_{1, t}^{\prime} & X_{2, t}^{\prime} & \cdots & X_{N-1, t}^{\prime} & X_{N, t}^{\prime}
\end{array}\right]^{\prime} ; \\
& Z_{i t-1}^{\prime}=\left[\begin{array}{llllll}
x_{i, t-1}^{1} & \bar{x}_{i, t-1}^{1} & \cdots & \cdots & x_{i, t-1}^{p} & \bar{x}_{i, t-1}^{p}
\end{array}\right]^{\prime} ;
\end{aligned}
$$

and $\bar{x}_{i, t-1}^{j}$ is the average of variable $x^{j}$ for country $i$.

Using $Z_{t}=W X_{t}$, we can now write the Global VECM as

$$
\Delta X_{t}=A B^{\prime} W X_{t-1}+\tilde{\Gamma}_{1} \Delta Z_{t-1}+\cdots+\tilde{\Gamma}_{k-1} \Delta Z_{t-k+1}+\tilde{\Phi} D_{t}+\tilde{\Gamma}_{0,1} \Delta \bar{X}_{t}+\tilde{\varepsilon}_{t} .
$$

Defining $\Gamma_{0,1}^{*} W \Delta X_{t} \equiv \tilde{\Gamma}_{0,1} \Delta \bar{X}_{t}$, and after some algebra, we obtain equation (14):

$$
\left[I-\Gamma_{0,1}^{*} W\right] \Delta X_{t}=A B^{\prime} W X_{t-1}+\tilde{\Gamma}_{1} \Delta Z_{t-1}+\cdots+\tilde{\Gamma}_{k-1} \Delta Z_{t-k+1}+\tilde{\Phi} D_{t}+\tilde{\varepsilon}_{t}
$$

Now, assume that we can calculate the inverse of matrix $\left[I-\Gamma_{0,1}^{*} W\right]$, we define

$$
\begin{aligned}
A^{*} & =\left[I-\Gamma_{0,1}^{*} W\right]^{-1} A, \\
\tilde{\Gamma}_{l}^{*} & =\left[I-\Gamma_{0,1}^{*} W\right]^{-1} \tilde{\Gamma}_{l}, \quad l=1, \ldots, k-1,
\end{aligned}
$$

and

$$
\tilde{\varepsilon}_{t}^{*}=\left[I-\Gamma_{0,1}^{*} W\right]^{-1} \tilde{\varepsilon}_{t}
$$

Then, we can solve the global model, yielding the solution to the global VECM, as shown in (15):

$$
\Delta X_{t}=A^{*} B^{\prime} W X_{t-1}+\tilde{\Gamma}_{1}^{*} \Delta Z_{t-1}+\cdots+\tilde{\Gamma}_{k-1}^{*} \Delta Z_{t-k+1}+\tilde{\Phi}^{*} D_{t}+\tilde{\varepsilon}_{t}^{*}
$$

So we obtain the transitory component as

$$
T_{t}^{\mathrm{GVAR}}=A^{*}\left(B^{\prime} W A^{*}\right)^{-1} B^{\prime} W X_{t}-\mathbb{E}\left[A^{*}\left(B^{\prime} W A^{*}\right)^{-1} B^{\prime} W X_{t}\right] .
$$

The permanent component is defined as the difference between the actual values of the series and the transitory component given in (16). The matrix given by (17) contains the weights that each cointegrated relationship will contribute to the transitory component:

$$
L F^{\mathrm{GVAR}}=A^{*}\left(B^{\prime} W A^{*}\right)^{-1} .
$$


The exchange rate misalignment can be calculated for country $i$ by picking the country's real exchange rate in vector $X_{t}$,

$$
m i s_{i, t}^{\mathrm{GVAR}} \equiv\left[\begin{array}{lllllll}
0 & \cdots & 0_{p(i-1)} & 1 & 0 & \ldots & 0
\end{array}\right] T_{t}^{\mathrm{GVAR}} .
$$

In the following section, we estimate the exchange rate misalignment of equations (4) and (18), and we compare the misalignment measures.

\section{Results}

\subsection{Dataset}

The database of this study is annual and covers the period from 1970 to 2012 . The foreign trade figures were collected from the IMF Direction of Trade Statistics (DOTS-IMF). We use these weights to calculate the external variables in the GVAR model. We collect the real effective exchange rate from the IMF's International Financial Statistics (IFS-IMF). We obtain the values of net foreign assets from Lane and Milesi-Ferretti (2007) and the IFS-IMF. The full sample consists of 33 countries, but we only analyze countries with data for all series and years during 1970 to 2012. This restricts the sample to 27 countries. Finally, we opt to work with end-of-period figures to avoid problems caused by data aggregation. In certain contexts, the temporal aggregation can cause significant distortions (Ghysels \& Miller, 2015; Taylor, 2001).

\subsection{Is there evidence of cointegration between real exchange rates and fundamen- tals?}

To assess the existence of cointegration between variables, we run the following cointegration tests: Engle and Granger (1987), Shin (1994), and Johansen (1988). The first two tests are univariate whereas the third is multivariate. The null hypothesis of the first test is absence of cointegration and alternative hypothesis is existence of cointegration. Second test is a confirmatory procedure whre the null hypothesis is existence of cointegration and alternative hypothesis is no cointegration. Trace and maximum eigenvalue tests proposed by Johansen if and how many cointegration relationships may exist.

Table 1 shows the results of the Engle and Granger (1987) and Shin (1994) cointegration tests, while Table 2 shows the results of the Johansen test for the sample countries. The null hypothesis of no cointegration is not rejected for many countries when looking at the cointegration of Engle and Granger or Johansen's tests. However, this conclusion is not corroborated by Shin's test. We do not reject the null hypothesis of cointegration at the $1 \%$ level of significance for most countries when both domestic and external variables are used. The rejection of the null hypothesis of cointegration is more frequent when we investigate only the relationship between real exchange rate and domestic fundamentals. These results suggests that external factors may explain real exchange rates in the long term for some countries. Since no formal rejection of the null hypothesis of cointegration occurs at the $1 \%$ level when all variables are used, we choose to work with the hypothesis that there exists one cointegrated relationship between the variables in specific countries' models. Another point to justify this choice is the cost of keeping irrelevant variable in econometric model compared to exclude a relevant variable. Omitting a relevant variable can induce bias in estimates of remaining parameters. 
Table 1. Results of univariate cointegration test.

\begin{tabular}{|c|c|c|c|c|c|c|c|}
\hline \multirow[b]{2}{*}{ CountrylLag } & \multicolumn{3}{|c|}{ Engle and Granger test } & \multirow[b]{2}{*}{ N. of regressors } & \multicolumn{3}{|c|}{ Shin cointegration tes } \\
\hline & 0 & 1 & 2 & & 1 & 2 & 3 \\
\hline Australia & -1.33 & -1.38 & -3.27 & & 0.276 & 0.149 & 0.131 \\
\hline Austria & -2.29 & -2.99 & -3.40 & & 0.287 & 0.167 & 0.161 \\
\hline Belgium & -2.97 & -3.86 & -3.84 & & 0.925 & 0.510 & $\underline{0.380}$ \\
\hline Brazil & -2.41 & -2.51 & -3.06 & & 0.300 & 0.069 & 0.070 \\
\hline Canada & -2.23 & -2.16 & -2.63 & & 0.171 & 0.178 & 0.055 \\
\hline China & -1.57 & -1.61 & -2.45 & & 0.367 & 0.372 & 0.199 \\
\hline Colombia & -3.35 & -2.51 & -2.50 & & 0.821 & 0.814 & 0.092 \\
\hline Denmark & -3.49 & -3.58 & -3.55 & & 0.163 & 0.306 & 0.289 \\
\hline Finland & -1.53 & -1.92 & -2.01 & & 0.054 & 0.066 & 0.066 \\
\hline France & -2.05 & -3.16 & -3.10 & & $\underline{0.576}$ & 0.290 & $\underline{0.272}$ \\
\hline Germany & -2.11 & -2.66 & -2.68 & & 0.788 & 0.312 & 0.355 \\
\hline Greece & -2.29 & -2.23 & -2.33 & & 0.350 & 0.087 & 0.088 \\
\hline India & -1.26 & -1.86 & -1.84 & & 0.202 & 0.237 & 0.146 \\
\hline Indonesia & -1.28 & -1.64 & -1.93 & & 0.344 & 0.059 & 0.053 \\
\hline Ireland & -1.91 & -2.90 & -3.09 & & 1.441 & 0.703 & $\underline{0.619}$ \\
\hline Italy & -3.37 & -3.48 & -3.94 & & $\underline{0.929}$ & $\underline{0.472}$ & 0.101 \\
\hline Japan & -2.33 & -3.63 & -3.55 & & 0.082 & 0.108 & 0.074 \\
\hline Mexico & -2.74 & -2.74 & -2.97 & & 0.417 & 0.179 & 0.068 \\
\hline Netherlands & -2.78 & -3.28 & -3.80 & & 0.307 & 0.349 & 0.089 \\
\hline Singapore & -1.98 & -2.96 & -2.98 & & 0.128 & $\underline{0.392}$ & 0.126 \\
\hline South Africa & -2.96 & -2.35 & -2.59 & & 0.365 & $\underline{0.389}$ & $\underline{0.384}$ \\
\hline Spain & -3.08 & -3.29 & -3.27 & & 0.244 & 0.170 & 0.070 \\
\hline Sweden & -1.31 & -2.28 & -2.28 & & 0.167 & 0.093 & 0.085 \\
\hline United Kingdom & -2.87 & -2.85 & -2.58 & & 1.192 & 0.234 & 0.245 \\
\hline United States & -3.04 & -3.04 & -3.31 & & 0.200 & 0.223 & 0.164 \\
\hline Uruguay & -2.48 & -2.50 & -2.46 & & 0.116 & 0.172 & 0.148 \\
\hline Turkey & -1.43 & -1.97 & -1.96 & & 0.390 & 0.159 & 0.138 \\
\hline \multicolumn{4}{|l|}{ Critical Values } & \multicolumn{4}{|l|}{ Critical Values } \\
\hline $10 \%$ & -3.07 & -3.45 & -3.83 & & & & \\
\hline $5 \%$ & -3.37 & -3.77 & -4.11 & $5 \%$ & 0.314 & 0.221 & 0.159 \\
\hline $1 \%$ & -3.96 & -4.31 & -4.73 & $1 \%$ & 0.533 & 0.380 & 0.271 \\
\hline
\end{tabular}


Table 2. Results of multivariate cointegration test.

\begin{tabular}{lccc}
\hline & \multicolumn{3}{c}{ Countries Trace Statistics: Null Hypothesis } \\
\cline { 2 - 4 } & N. of vectors & Absence & One vector \\
\hline Australia & 1 & 40.21 & 10.14 \\
Austria & 1 & 30.01 & 12.93 \\
Belgium & 0 & 15.88 & 3.21 \\
Brazil & 1 & 35.69 & 12.60 \\
Canada & 0 & 11.20 & 4.58 \\
China & 1 & 39.88 & 8.38 \\
Colombia & 0 & 26.91 & 12.70 \\
Denmark & 0 & 24.09 & 5.30 \\
Finland & 0 & 14.84 & 5.42 \\
France & 0 & 21.10 & 2.48 \\
Germany & 0 & 14.94 & 2.64 \\
Greece & 0 & 17.70 & 5.46 \\
India & 1 & 28.66 & 5.90 \\
Indonesia & 0 & 25.60 & 3.30 \\
Ireland & 0 & 15.78 & 2.99 \\
Italy & 0 & 18.21 & 5.73 \\
Japan & 0 & 26.89 & 6.55 \\
Mexico & 0 & 27.25 & 5.93 \\
Netherlands & 0 & 24.22 & 7.22 \\
Singapore & 0 & 17.37 & 6.40 \\
South Africa & 1 & 32.31 & 10.03 \\
Spain & 0 & 23.35 & 9.63 \\
Sweden & 0 & 22.55 & 6.32 \\
United Kingdom & 0 & 21.30 & 6.17 \\
United States & 0 & 23.25 & 8.83 \\
Uruguay & 0 & 16.05 & 5.16 \\
Turkey & 1 & 28.11 & 6.66 \\
\hline & & & \\
\hline
\end{tabular}

The specification may be improved by adding other variables. For example, a variable that controls the possible Balassa-Samuelson effect may alter the results towards finding stronger evidence of cointegration. ${ }^{5}$

\subsection{Is there evidence of global effects?}

This section attempts to answer the question of whether the model with external factors is better than the model without these factors. We compare eight different specifications. We consider models with complete interdependence, in other words, that have external factors, in the short and long term dynamics, similar to the equation (12). There are models in which interdependence is allowed only in the long term. In another specification, we allow interdependence only on short-term dynamics. Finally, there are models in which no interdependence is allowed. We estimate the models also allowing a structure with or without

\footnotetext{
${ }^{5}$ In this study, we could have analyzed a broader set of information using variables to control for the Balassa-Samuelson effect, similar to Kubota (2009) and Alberola et al. (1999). However, the number of countries in the sample would have been further reduced. We opt to explore a longer sample with a wider number of countries rather than a restricted sample with more variables. The inclusion of a variable to control for the Balassa-Samuelson effect reduces the sample in both the temporal and cross-sectional dimensions.
} 
common cycles. ${ }^{6}$ We compare these eight models using the Schwarz (SC), Hannan-Quinn (HQ), and Akaike information criteria (AIC).

Table 3 presents a detailed description of the models and all information criteria. Options 3 and 4 consist of models with no interdependence. The evidence in favor of interdependence varies between countries. According to all information criteria, there is no evidence of interdependence for the following countries: Australia, Ireland, India, Netherlands, and Turkey. For other countries, there is evidence of interdependence in the short and/or long term. Thus, we can conclude that statistical evidence corroborates the hypothesis of interdependence for a large group of countries. The next step in the analysis is to assess the relevance of global and domestic factors to exchange rate misalignment estimate.

\subsection{Calculating exchange rate misalignment using the GVECM}

This section describes the results of the GVECM estimation. Table 6 shows the estimated cointegrated vectors for each country. Table 4 shows the results of the estimate loading factor given by (17) for real exchange rate equation. The value in line $i$ and column $j$ represents the weight of the error correction mechanism of country $j$ that will be used to calculate the misalignment for country $i$. For example, we can check that the United States and Germany columns contain many non-zero terms. This suggests strong linkages between these economies and others economies analyzed in the sample. In the case of Germany, there seems to be a strong effect in eurozone countries. Brazil is an example of the opposite case. Here, the Brazilian exchange rate misalignment causes minor effects on all countries other than Uruguay. Although Brazil is a large economy, its global share is relatively small. Intuitively, the Brazilian economy is affected by others countries' disequilibrium, but its own disequilibrium does not affect others countries. The United States exchange rate misalignment may generate quite small effects on eurozone countries.

Table 5 compares the results of the exchange rate misalignment using the traditional and GVAR methodologies. In general, the estimate misalignment tends to have the same sign for almost $67 \%$ of the sample. There are $1,161(27 \times 43)$ estimate of exchange rate misalignments, across all countries and periods. For the United States, the results are virtually the same in terms of sign and magnitude. The overall picture does not change when the comparison is made using the magnitude rather than the sign of the exchange rate misalignment. We compute the proportion of each case out of the total, where the estimate misalignments for both models have the same sign and absolute value above $10 \%$, or different signs but absolute an below $10 \%$. In the $57 \%$ of cases, these criteria were satisfied. However, in about $43 \%$ of cases, the estimates are not the same. The results in Table 5 suggest that quite different results can be obtained from the GVAR. The dynamics of real exchange rates in these countries cannot be seen as detached from the rest of world, or at least from their main trading partners. Table 6 shows the estimates of all parameters necessary to solve the GVAR.

Table 7 provides information about the source of the differences between the two methodologies. First, the coefficient of the NFA variable changes quite significantly for many countries. This may explain part of the change in the results and highlights the importance of investigating the main drivers of real exchange rates in the long run. However, there are countries where the coefficient hardly changes at all, but the external variables cause

\footnotetext{
${ }^{6}$ See Hecq, Palm, and Urbain (2000) and Hecq, Palm, and Urbain (2002) for a common cycle definition, a discussion, and its relationship to permanent and transitory decomposition.
} 
Table 3. Results of the tests for interdependence.

\begin{tabular}{|c|c|c|c|c|}
\hline \multirow[b]{2}{*}{ Models } & \multirow[b]{2}{*}{ Common Features } & \multicolumn{2}{|c|}{ External Variables in the Model } & \multirow[b]{2}{*}{ Interdependence } \\
\hline & & Short Run & Long Run & \\
\hline 1 & No & Yes & Yes & Yes, Both types \\
\hline 2 & Yes & Yes & Yes & Yes, Both types \\
\hline 3 & No & No & No & No \\
\hline 4 & Yes & No & No & No \\
\hline 5 & No & Yes & No & Yes, Short Run \\
\hline 6 & Yes & Yes & No & Yes, Short Run \\
\hline 7 & No & No & Yes & Yes, Long Run \\
\hline \multirow[t]{2}{*}{8} & Yes & No & Yes & Yes, Long Run \\
\hline & \multicolumn{3}{|c|}{ Best Model - Information Criteria } & \\
\hline Country & SC & HQ & AIC & \\
\hline Australia & 8 & 8 & 2 & \\
\hline Austria & 6 & 6 & 6 & \\
\hline Belgium & 6 & 6 & 1 & \\
\hline Brazil & 8 & 8 & 8 & \\
\hline Canada & 4 & 4 & 5 & \\
\hline China & 8 & 8 & 8 & \\
\hline Colombia & 6 & 6 & 2 & \\
\hline Denmark & 4 & 4 & 2 & \\
\hline Finland & 3 & 3 & 2 & \\
\hline France & 8 & 1 & 1 & \\
\hline Germany & 4 & 4 & 4 & \\
\hline Greece & 4 & 4 & 4 & \\
\hline India & 8 & 8 & 8 & \\
\hline Ireland & 6 & 6 & 6 & \\
\hline Italy & 8 & 8 & 8 & \\
\hline Japan & 6 & 1 & 1 & \\
\hline Mexico & 4 & 8 & 8 & \\
\hline Netherlands & 2 & 2 & 2 & \\
\hline Singapore & 4 & 4 & 5 & \\
\hline South Africa & 8 & 2 & 2 & \\
\hline Spain & 4 & 4 & 2 & \\
\hline Sweden & 6 & 2 & 2 & \\
\hline United Kingdom & 6 & 5 & 5 & \\
\hline United States & 6 & 6 & 5 & \\
\hline Uruguay & 4 & 6 & 6 & \\
\hline Turkey & 6 & 2 & 2 & \\
\hline
\end{tabular}


Table 4. Loading factor for calculating exchange rate misalignment from the GVAR model.

\begin{tabular}{|c|c|c|c|c|c|c|c|c|c|c|c|c|c|c|}
\hline & \multicolumn{14}{|c|}{ Error Correction Mechanism } \\
\hline & AUS $^{a}$ & AUT & BEL & BRA & CAN & CHN & $\mathrm{COL}$ & DEN & FIN & FRA & DEU & GRC & IND & IRL \\
\hline Australia & 0.55 & 0.00 & 0.04 & -0.01 & -0.04 & 0.01 & 0.00 & 0.02 & 0.00 & 0.24 & 0.08 & 0.01 & -0.01 & 0.03 \\
\hline Austria & 0.00 & 0.13 & -0.01 & 0.00 & 0.01 & 0.00 & 0.00 & -0.04 & 0.00 & -0.17 & 0.34 & 0.01 & 0.00 & 0.01 \\
\hline Belgium & 0.01 & 0.00 & 0.97 & 0.00 & 0.01 & 0.00 & 0.00 & -0.09 & 0.00 & -0.32 & 0.31 & 0.01 & 0.02 & 0.04 \\
\hline Brazil & 0.02 & -0.01 & -0.16 & 1.26 & 0.24 & -0.04 & 0.02 & -0.18 & 0.00 & -1.94 & -0.02 & 0.00 & 0.03 & 0.09 \\
\hline Canada & 0.00 & 0.00 & 0.00 & 0.00 & 1.02 & 0.00 & 0.00 & 0.00 & 0.00 & -0.03 & -0.01 & 0.00 & 0.00 & 0.00 \\
\hline China & -0.05 & 0.00 & 0.00 & -0.06 & -0.07 & -0.22 & 0.00 & -0.02 & 0.00 & 0.34 & -0.09 & 0.00 & -0.05 & 0.04 \\
\hline Colombia & 0.01 & 0.00 & 0.06 & 0.06 & 0.19 & -0.01 & 0.53 & -0.04 & 0.00 & -0.36 & 0.36 & 0.01 & 0.02 & 0.01 \\
\hline Denmark & 0.00 & 0.03 & 0.25 & 0.02 & 0.05 & -0.01 & 0.00 & 0.92 & -0.03 & 1.46 & 1.02 & 0.08 & 0.01 & 0.00 \\
\hline Finland & 0.01 & 0.04 & 0.47 & 0.03 & 0.08 & -0.01 & 0.00 & -0.37 & 0.00 & 2.83 & 1.11 & 0.12 & 0.02 & 0.07 \\
\hline France & 0.02 & 0.08 & 1.11 & 0.06 & 0.16 & -0.02 & 0.00 & -0.41 & -0.01 & 7.01 & 2.55 & 0.28 & 0.05 & 0.13 \\
\hline Germany & 0.00 & 0.01 & 0.10 & 0.01 & 0.02 & 0.00 & 0.00 & -0.03 & 0.00 & 0.29 & 1.20 & 0.02 & 0.00 & 0.01 \\
\hline Greece & 0.00 & 0.00 & -0.04 & 0.00 & 0.00 & 0.00 & 0.00 & 0.01 & 0.00 & -0.33 & 0.00 & 0.05 & 0.00 & -0.01 \\
\hline India & 0.05 & 0.00 & -0.01 & 0.04 & 0.18 & -0.03 & 0.01 & 0.02 & 0.00 & -1.57 & -0.13 & -0.01 & 1.09 & -0.18 \\
\hline Ireland & -0.04 & -0.02 & -0.40 & -0.03 & -0.09 & 0.01 & 0.00 & -0.10 & 0.01 & -1.72 & -0.89 & -0.07 & -0.04 & 0.83 \\
\hline Italy & -0.02 & -0.02 & -0.87 & -0.07 & -0.11 & 0.02 & 0.00 & 0.23 & 0.01 & -5.04 & -2.04 & -0.05 & -0.04 & 0.01 \\
\hline Japan & -0.02 & 0.00 & -0.03 & -0.02 & -0.14 & 0.04 & 0.00 & 0.04 & 0.00 & -0.08 & -0.12 & -0.02 & -0.01 & -0.01 \\
\hline Mexico & -0.01 & 0.00 & 0.00 & -0.01 & -0.12 & 0.00 & 0.00 & 0.00 & 0.00 & 0.03 & 0.02 & 0.00 & 0.00 & 0.02 \\
\hline Netherlands & 0.01 & 0.00 & 0.06 & 0.00 & 0.00 & 0.00 & 0.00 & -0.10 & 0.00 & -0.39 & 0.32 & 0.01 & 0.00 & 0.04 \\
\hline Singapore & 0.02 & 0.00 & 0.01 & 0.00 & 0.01 & 0.00 & 0.00 & 0.00 & 0.00 & 0.03 & 0.02 & 0.00 & 0.01 & 0.00 \\
\hline Spain & 0.00 & -0.07 & -0.94 & -0.06 & -0.11 & 0.02 & -0.01 & 0.34 & 0.01 & -6.16 & -2.10 & -0.21 & -0.03 & 0.03 \\
\hline Sweden & 0.02 & 0.03 & 0.51 & 0.03 & 0.09 & -0.01 & 0.00 & -1.68 & -0.06 & 3.00 & 0.60 & 0.11 & 0.03 & 0.15 \\
\hline UK & -0.05 & -0.03 & -0.43 & -0.03 & -0.15 & 0.01 & 0.00 & 0.18 & 0.01 & -1.30 & -0.99 & -0.09 & -0.05 & -0.27 \\
\hline USA & 0.01 & 0.00 & 0.01 & 0.01 & 0.13 & 0.00 & 0.00 & -0.01 & 0.00 & 0.02 & 0.01 & 0.00 & 0.00 & -0.01 \\
\hline Uruguay & 0.02 & 0.01 & 0.29 & -0.72 & 0.06 & -0.02 & 0.00 & 0.08 & -0.01 & 1.24 & 0.77 & 0.15 & 0.04 & 0.11 \\
\hline South Africa & -0.02 & 0.01 & 0.07 & -0.01 & 0.00 & 0.05 & 0.00 & -0.03 & 0.00 & 1.11 & 0.07 & 0.02 & -0.10 & 0.05 \\
\hline Indonesia & -0.05 & 0.00 & 0.00 & 0.00 & 0.02 & 0.01 & 0.00 & -0.03 & 0.00 & 0.25 & 0.02 & 0.01 & -0.06 & 0.02 \\
\hline \multirow[t]{2}{*}{ Turkey } & 0.01 & 0.02 & -0.04 & 0.00 & 0.04 & -0.01 & 0.00 & -0.05 & 0.00 & -0.75 & 0.62 & 0.08 & 0.01 & 0.05 \\
\hline & ITA & JAP & MEX & NLD & SGP & ESP & SWE & GBR & USA & URY & ZAF & IDN & TUR & \\
\hline Australia & 0.04 & 0.02 & -0.02 & 0.02 & 0.05 & 0.02 & 0.00 & -0.03 & -0.08 & 0.00 & 0.00 & 0.00 & 0.00 & \\
\hline Austria & 0.05 & 0.00 & 0.00 & 0.02 & 0.00 & 0.00 & 0.00 & -0.01 & 0.01 & 0.00 & 0.00 & 0.00 & 0.00 & \\
\hline Belgium & -0.05 & 0.01 & 0.00 & 0.30 & 0.00 & 0.00 & 0.00 & -0.05 & 0.03 & 0.00 & 0.00 & 0.00 & 0.00 & \\
\hline Brazil & -0.35 & 0.16 & 0.23 & 0.54 & -0.02 & -0.02 & 0.00 & -0.09 & 0.39 & 0.05 & 0.01 & 0.00 & 0.00 & \\
\hline Canada & 0.00 & 0.02 & 0.01 & 0.00 & 0.00 & 0.00 & 0.00 & 0.00 & 0.11 & 0.00 & 0.00 & 0.00 & 0.00 & \\
\hline China & -0.06 & -0.96 & -0.05 & -0.03 & 0.06 & 0.01 & 0.00 & -0.03 & -0.29 & 0.00 & -0.01 & 0.01 & 0.00 & \\
\hline Colombia & 0.02 & 0.15 & 0.14 & 0.14 & -0.01 & 0.07 & 0.00 & 0.00 & 0.66 & 0.00 & 0.00 & 0.00 & 0.00 & \\
\hline Denmark & 0.36 & 0.06 & 0.03 & 0.32 & 0.01 & 0.17 & -0.03 & -0.03 & 0.07 & 0.00 & 0.00 & 0.00 & 0.00 & \\
\hline Finland & 0.52 & 0.02 & 0.04 & 0.42 & 0.02 & 0.29 & 0.03 & -0.09 & 0.11 & 0.00 & 0.01 & 0.00 & 0.00 & \\
\hline France & 1.27 & 0.06 & 0.09 & 0.90 & 0.04 & 0.68 & 0.00 & -0.18 & 0.23 & 0.00 & 0.02 & -0.01 & 0.01 & \\
\hline Germany & 0.12 & 0.00 & 0.01 & 0.09 & 0.00 & 0.05 & 0.00 & -0.01 & 0.03 & 0.00 & 0.00 & 0.00 & 0.00 & \\
\hline Greece & 0.09 & 0.00 & 0.00 & -0.02 & 0.00 & -0.03 & 0.00 & 0.01 & 0.00 & 0.00 & 0.00 & 0.00 & 0.00 & \\
\hline India & -0.04 & 0.87 & 0.06 & 0.03 & 0.18 & -0.13 & 0.01 & 0.12 & 0.57 & 0.00 & 0.02 & -0.02 & 0.00 & \\
\hline Ireland & -0.48 & -0.07 & -0.04 & -0.20 & 0.01 & -0.22 & 0.02 & 0.25 & -0.14 & 0.00 & -0.03 & 0.00 & 0.00 & \\
\hline Italy & 0.16 & -0.05 & -0.08 & -0.68 & -0.03 & -0.55 & 0.00 & 0.04 & -0.20 & 0.00 & -0.02 & 0.00 & 0.00 & \\
\hline Japan & -0.01 & 1.16 & -0.07 & -0.06 & -0.15 & -0.02 & 0.00 & 0.01 & -0.22 & 0.00 & 0.00 & 0.01 & 0.00 & \\
\hline Mexico & 0.00 & -0.01 & 1.42 & 0.03 & 0.04 & 0.00 & 0.00 & -0.02 & 0.07 & 0.00 & 0.00 & 0.00 & 0.00 & \\
\hline Netherlands & -0.07 & 0.00 & 0.00 & 0.87 & 0.00 & -0.01 & 0.00 & -0.04 & 0.01 & 0.00 & 0.00 & 0.00 & 0.00 & \\
\hline Singapore & 0.01 & -0.01 & 0.01 & 0.01 & 1.13 & 0.00 & 0.00 & 0.00 & 0.03 & 0.00 & 0.00 & -0.01 & 0.00 & \\
\hline Spain & -1.49 & -0.04 & -0.10 & -0.70 & -0.05 & 0.39 & -0.01 & 0.02 & -0.17 & -0.01 & -0.01 & 0.00 & 0.00 & \\
\hline Sweden & 0.42 & -0.04 & 0.05 & 0.38 & 0.03 & 0.28 & 0.02 & -0.16 & 0.13 & 0.00 & 0.02 & 0.00 & 0.00 & \\
\hline UK & -0.39 & -0.09 & -0.06 & -0.43 & -0.03 & -0.23 & 0.00 & 0.16 & -0.24 & 0.00 & -0.03 & 0.00 & 0.00 & \\
\hline USA & 0.01 & 0.03 & 0.06 & 0.00 & -0.01 & 0.00 & 0.00 & 0.01 & 0.43 & 0.00 & 0.00 & 0.00 & 0.00 & \\
\hline Uruguay & 0.20 & 0.10 & 0.04 & 0.24 & 0.01 & 0.15 & 0.00 & -0.11 & 0.20 & 0.94 & 0.01 & 0.00 & 0.00 & \\
\hline South Africa & 0.15 & -0.22 & 0.00 & -0.04 & -0.01 & 0.04 & 0.00 & -0.02 & -0.02 & 0.00 & 0.41 & 0.00 & 0.00 & \\
\hline Indonesia & -0.01 & -1.10 & 0.01 & 0.00 & 0.05 & 0.00 & 0.00 & -0.02 & -0.11 & 0.00 & 0.00 & -0.16 & 0.00 & \\
\hline Turkey & -0.01 & 0.01 & 0.01 & 0.06 & 0.01 & 0.00 & 0.00 & -0.06 & 0.07 & 0.00 & 0.00 & 0.00 & 0.02 & \\
\hline
\end{tabular}

a ISO alpha-3 country codes: AUS (Australia), AUT (Austria), BEL (Belgium), BRA (Brazil), CAN (Canada), CHN (China), COL (Colombia), DEN (Denmark), FIN (Finland), FRA (France), DEU (Germany), GRC (Greece), IND (India), IRL (IRELAND), ITA (Italy), JPN (Japan), MEX (Mexico), NLD (Netherlands), SGP (Singapore), ESP (Spain), SWE (Sweden), GBR (United Kingdom), USA (United States of America), URY (Uruguay), ZAF (South Africa), IDN (Indonesia), TUR (Turkey). 
Table 5. Comparing exchanges rate misalignment estimates.

\begin{tabular}{lcc}
\hline & \multicolumn{2}{c}{ Percentage of case where: } \\
\cline { 2 - 3 } & $\begin{array}{c}\text { Sign of misalignment } \\
\text { is the same }\end{array}$ & $\begin{array}{c}\text { Magnitude of misalignment } \\
\text { is the same }\end{array}$ \\
& $(\%)$ & $(\%)$ \\
\hline Australia & 58.14 & 76.74 \\
Austria & 48.84 & 86.05 \\
Belgium & 65.12 & 81.40 \\
Brazil & 74.42 & 60.47 \\
Canada & 79.07 & 51.16 \\
China & 62.79 & 25.58 \\
Colombia & 67.44 & 76.74 \\
Denmark & 69.77 & 48.84 \\
Finland & 55.81 & 39.53 \\
France & 67.44 & 48.84 \\
Germany & 93.02 & 79.07 \\
Greece & 76.74 & 55.81 \\
India & 60.47 & 44.19 \\
Ireland & 60.47 & 51.16 \\
Italy & 51.16 & 34.88 \\
Japan & 60.47 & 32.56 \\
Mexico & 81.40 & 74.42 \\
Netherlands & 65.12 & 83.72 \\
Singapore & 88.37 & 90.70 \\
Spain & 62.79 & 27.91 \\
Sweden & 74.42 & 46.51 \\
United Kingdom & 62.79 & 41.86 \\
United States & 79.07 & 86.05 \\
Uruguay & 81.40 & 60.47 \\
South Africa & 55.81 & 41.86 \\
Indonesia & 41.86 & 58.14 \\
Turkey & 55.81 & 44.19 \\
\hline Total & 66.67 & in modulus or \\
\hline a If both estimates give a value of misalignment above & \\
below 10\% in modulus simultaneously. & & \\
& & \\
& &
\end{tabular}

changes in the magnitude of the exchange misalignment estimate. Brazil is a good example. Although there is a minor change in the NFA coefficient when external variables are included in the model, they add relevant information to the long run level of the exchange rate. The misalignment of the exchange rate for both models is different after introducing foreign variables.

We show exchange rate misalignment estimates from traditional and GVAR methodologies in Figures 1 and 2. The case of Brazil and USA are shown as examples. For the USA, estimates of real exchange rate misalignment by traditional and GVAR methodologies differ in magnitude for most of the sample according to Figure 1. The amplitude of misalignment is lower by GVAR model. The Brazilian estimates of misalignment by traditional and GVAR methodologies are quite similar until 2008, according to Figure 2. In the end of the sample, particularly after the financial crisis of 2008, the results are different for both of the countries. 
Table 6. Coefficient estimates for each country model used to solve the GVAR.

\begin{tabular}{|c|c|c|c|c|c|c|c|c|c|c|c|}
\hline \multirow[b]{2}{*}{ Country } & \multicolumn{2}{|c|}{ Loading Matrix } & \multicolumn{5}{|c|}{ Cointegrated Vectors } & \multicolumn{4}{|c|}{ Contemporaneous Effect } \\
\hline & $\alpha_{i 1}$ & $\alpha_{i 2}$ & $\beta_{i, \mathrm{RER}}$ & $\beta_{i, \mathrm{NFA}}$ & $\beta_{i, \mathrm{RERW}}$ & $\beta_{i, \mathrm{NFAw}}$ & $\beta_{i, \text { Constant }}$ & $C_{i, 11}$ & $C_{i, 12}$ & $C_{i, 21}$ & $C_{i, 22}$ \\
\hline Australia & -0.45 & 0.27 & 1 & -1.34 & 0.71 & -2.07 & -8.21 & -0.55 & 0.55 & 0.54 & -0.66 \\
\hline Austria & -0.07 & -0.37 & 1 & 1.31 & 0.23 & -2.25 & -5.43 & 0.90 & -0.10 & -0.04 & 0.06 \\
\hline Belgium & -0.39 & -0.03 & 1 & -0.13 & -0.86 & -0.77 & -0.60 & 1.11 & -0.23 & -0.29 & 0.47 \\
\hline Brazil & -0.89 & -0.18 & 1 & -1.19 & 0.85 & -3.21 & -9.18 & -0.25 & 2.74 & 0.82 & -0.44 \\
\hline Canada & -0.16 & -0.03 & 1 & 0.00 & -0.37 & 0.11 & -2.79 & -0.02 & 1.22 & 0.10 & -0.49 \\
\hline China & 0.06 & 0.04 & 1 & -8.88 & -18.54 & 14.25 & 80.15 & 0.42 & 0.10 & -0.39 & 0.41 \\
\hline Colombia & -0.08 & 0.01 & 1 & -6.45 & 4.47 & 0.48 & -26.80 & 0.39 & 1.58 & 0.10 & -0.14 \\
\hline Denmark & -0.05 & 0.29 & 1 & 0.10 & -2.26 & 1.03 & 6.12 & -0.01 & 0.46 & -1.09 & -0.78 \\
\hline Finland & 0.00 & 0.41 & 1 & -1.27 & -2.48 & 7.74 & 6.92 & 0.62 & 0.47 & 0.41 & 5.56 \\
\hline France & -0.82 & 0.59 & 1 & 0.18 & -1.49 & 0.18 & 2.24 & 1.15 & -0.62 & 0.42 & -0.52 \\
\hline Germany & -0.45 & -0.18 & 1 & -0.15 & -0.80 & 0.14 & -0.89 & 0.52 & -0.96 & 0.33 & 0.15 \\
\hline Greece & 0.00 & -0.31 & 1 & 0.36 & -1.84 & -1.81 & 4.28 & 0.61 & -0.25 & -0.49 & -0.69 \\
\hline India & -0.32 & -0.03 & 1 & -1.42 & -7.74 & 0.49 & 31.01 & 1.87 & 0.63 & 0.09 & -0.27 \\
\hline Ireland & -0.52 & 0.17 & 1 & 0.30 & -0.68 & 2.44 & -1.19 & -0.44 & -0.90 & 0.75 & -4.21 \\
\hline Italy & -0.46 & 0.14 & 1 & 0.09 & 2.25 & -2.56 & -15.09 & -0.17 & 0.62 & -0.39 & -0.01 \\
\hline Japan & -0.48 & -0.11 & 1 & 0.14 & 1.41 & 0.70 & -11.19 & -1.36 & -1.91 & -0.19 & -0.53 \\
\hline Mexico & -1.05 & -0.40 & 1 & -0.83 & -0.41 & 0.84 & -2.95 & 0.98 & 0.42 & 0.06 & -0.13 \\
\hline Netherlands & -0.21 & -0.55 & 1 & 0.00 & -0.56 & -1.85 & -1.94 & 1.33 & -0.05 & -1.37 & 1.72 \\
\hline Singapore & -0.20 & -0.45 & 1 & -0.05 & -0.51 & 0.08 & -2.19 & 0.64 & 0.24 & -0.80 & -2.65 \\
\hline Spain & -0.36 & -0.17 & 1 & 0.16 & 2.97 & -4.67 & -18.32 & 0.29 & 0.82 & -0.88 & 1.40 \\
\hline Sweden & -0.04 & -0.27 & 1 & 2.07 & -8.08 & -1.09 & 32.92 & 0.59 & -0.23 & 2.26 & 0.13 \\
\hline UK & -0.04 & 0.09 & 1 & -3.56 & 9.64 & -12.90 & -50.20 & -2.27 & 1.22 & -0.10 & -2.19 \\
\hline USA & -0.12 & -0.06 & 1 & 2.35 & -2.59 & 3.40 & 7.75 & -0.25 & 0.46 & 0.59 & -0.68 \\
\hline Uruguay & -0.42 & 0.02 & 1 & -1.85 & 2.16 & -3.16 & -15.47 & -0.60 & -0.53 & 0.09 & 1.19 \\
\hline South Africa & -0.41 & 0.14 & 1 & -4.45 & -7.39 & -1.89 & 28.86 & 1.98 & -3.85 & -0.72 & -0.32 \\
\hline Indonesia & 0.05 & 0.07 & 1 & -5.11 & -10.19 & 4.05 & 39.97 & -1.60 & -0.59 & -1.94 & -3.51 \\
\hline Turkey & -0.02 & -0.05 & 1 & 17.13 & -53.64 & 9.75 & 249.77 & 1.10 & 0.88 & 1.42 & -1.75 \\
\hline
\end{tabular}

Table 7. Comparing the cointegrated coefficient of the GVAR and traditional methodologies.

\begin{tabular}{|c|c|c|c|c|c|c|c|c|c|c|c|}
\hline & \multicolumn{10}{|c|}{ Cointegrated Relationship } & \multirow{3}{*}{$\begin{array}{l}\text { Difference between NFA } \\
\text { long run coefficients } \\
\text { in both models }\end{array}$} \\
\hline & \multicolumn{5}{|c|}{ GVAR } & \multicolumn{5}{|c|}{ Traditional Methodologhy } & \\
\hline & RER & NFA & RERw & NFAw & Constant & RER & NFA & RERw & NFAw & Constant & \\
\hline Australia & 1 & -1.3 & 0.7 & -2.1 & -8.2 & 1 & -0.9 & 0 & 0 & -4.9 & -0.4 \\
\hline Austria & 1 & 1.3 & 0.2 & -2.2 & -5.4 & 1 & -0.1 & 0 & 0 & -4.6 & 1.4 \\
\hline Belgium & 1 & -0.1 & -0.9 & -0.8 & -0.6 & 1 & 0.0 & 0 & 0 & -4.6 & -0.2 \\
\hline Brazil & 1 & -1.2 & 0.9 & -3.2 & -9.2 & 1 & -1.3 & 0 & 0 & -5.1 & 0.1 \\
\hline Canada & 1 & 0.0 & -0.4 & 0.1 & -2.8 & 1 & 1.0 & 0 & 0 & -4.3 & -1.0 \\
\hline China & 1 & -8.9 & -18.5 & 14.2 & 80.2 & 1 & -2.1 & 0 & 0 & -4.5 & -6.8 \\
\hline Colombia & 1 & -6.5 & 4.5 & 0.5 & -26.8 & 1 & -5.0 & 0 & 0 & -5.5 & -1.4 \\
\hline Denmark & 1 & 0.1 & -2.3 & 1.0 & 6.1 & 1 & -0.2 & 0 & 0 & -4.6 & 0.3 \\
\hline Finland & 1 & -1.3 & -2.5 & 7.7 & 6.9 & 1 & -0.3 & 0 & 0 & -4.8 & -0.9 \\
\hline France & 1 & 0.2 & -1.5 & 0.2 & 2.2 & 1 & -0.3 & 0 & 0 & -4.6 & 0.5 \\
\hline Germany & 1 & -0.2 & -0.8 & 0.1 & -0.9 & 1 & -0.1 & 0 & 0 & -4.6 & -0.1 \\
\hline Greece & 1 & 0.4 & -1.8 & -1.8 & 4.3 & 1 & 0.0 & 0 & 0 & -4.3 & 0.3 \\
\hline India & 1 & -1.4 & -7.7 & 0.5 & 31.0 & 1 & -8.1 & 0 & 0 & -5.6 & 6.7 \\
\hline Ireland & 1 & 0.3 & -0.7 & 2.4 & -1.2 & 1 & 0.2 & 0 & 0 & -4.4 & 0.1 \\
\hline Italy & 1 & 0.1 & 2.3 & -2.6 & -15.1 & 1 & 0.2 & 0 & 0 & -4.6 & -0.1 \\
\hline Japan & 1 & 0.1 & 1.4 & 0.7 & -11.2 & 1 & 0.3 & 0 & 0 & -4.5 & -0.1 \\
\hline Mexico & 1 & -0.8 & -0.4 & 0.8 & -3.0 & 1 & -0.4 & 0 & 0 & -4.7 & -0.4 \\
\hline Netherlands & 1 & 0.0 & -0.6 & -1.8 & -1.9 & 1 & -0.2 & 0 & 0 & -4.6 & 0.2 \\
\hline Singapore & 1 & -0.1 & -0.5 & 0.1 & -2.2 & 1 & 0.0 & 0 & 0 & -4.6 & 0.0 \\
\hline Spain & 1 & 0.2 & 3.0 & -4.7 & -18.3 & 1 & 0.1 & 0 & 0 & -4.4 & 0.0 \\
\hline Sweden & 1 & 2.1 & -8.1 & -1.1 & 32.9 & 1 & -1.0 & 0 & 0 & -4.9 & 3.1 \\
\hline United Kingdom & 1 & -3.6 & 9.6 & -12.9 & -50.2 & 1 & -0.2 & 0 & 0 & -4.8 & -3.3 \\
\hline United States & 1 & 2.4 & -2.6 & 3.4 & 7.8 & 1 & -0.5 & 0 & 0 & -4.7 & 2.8 \\
\hline Uruguay & 1 & -1.9 & 2.2 & -3.2 & -15.5 & 1 & -1.3 & 0 & 0 & -4.9 & -0.5 \\
\hline South Africa & 1 & -4.5 & -7.4 & -1.9 & 28.9 & 1 & 1.5 & 0 & 0 & -4.5 & -5.9 \\
\hline Indonesia & 1 & -5.1 & -10.2 & 4.1 & 40.0 & 1 & -4.0 & 0 & 0 & -6.6 & -1.1 \\
\hline Turkey & 1 & 17.1 & -53.6 & 9.7 & 249.8 & 1 & 0.2 & 0 & 0 & -4.2 & 16.9 \\
\hline
\end{tabular}




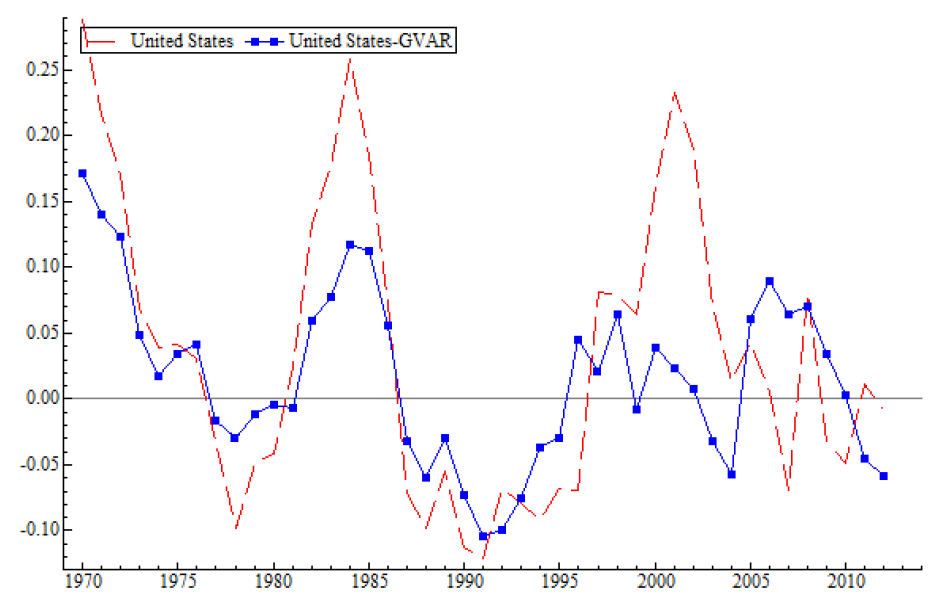

Figure 1. Real exchange rate misalignment estimate - GVAR versus traditional methodology United States.

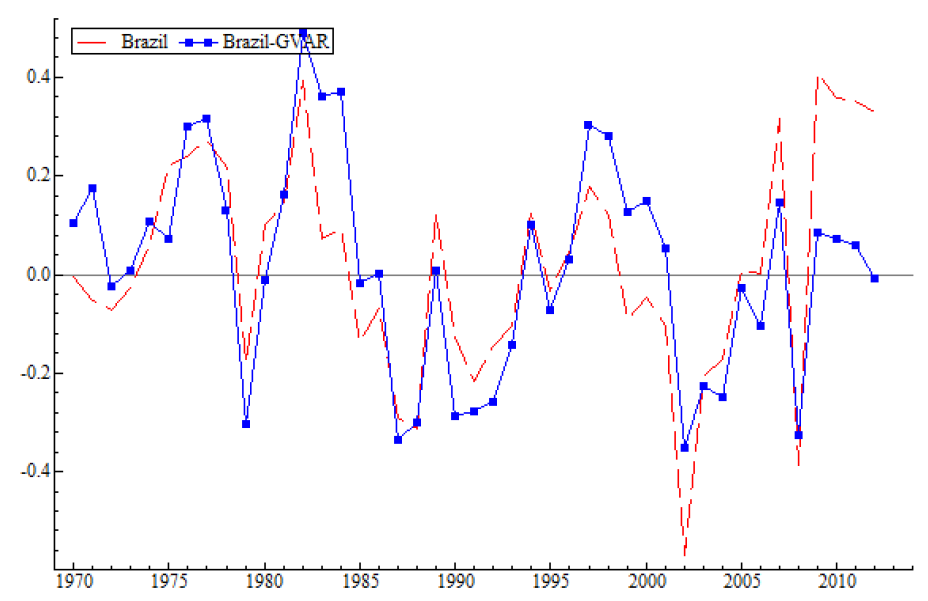

Figure 2. Real exchange rate misalignment estimate - GVAR versus traditional methodology Brazil.

In a recent paper, Ericsson and Reisman (2012) proposes a refinement of the GVAR approach using a model selection procedure called Autometrics. ${ }^{7}$ This refinement allows one to search for points of instability and structural changes in the modeling process. It is also possible to incorporate a wider range of information sets in each country model. However, this must occur within a rigorous general-to-specific econometric modeling approach in the spirit of the London School of Economics (LSE) tradition developed by David Hendry. This reduces the possibility of criticism that a time series analysis can only manage a few real exchange rate determinants at a time, as compared to panel models. By using the GVAR refinement proposed by Ericsson and Reisman (2012), it is possible, for example, to match the merits of the IMF approach, with its wide range of variables, to a panel with the merits of a global model. One can opt to model different set fundamentals for each country.

${ }^{7}$ See Doornik (2009). 
The interdependence among countries is introduced in GVAR by adding trade weighted foreign variables in the model of each specific country. We opt to use Autometrics search algorithm to check if these variables explain the dynamics of each country models. The traditional methodology can be extended in many directions. The GVAR is one possible way but not the only one. We decide to construct indicators functions (impulse, step and time trend dummies) to allow for structural change in mean of the process. We also run principal components analysis on all first differences of the logarithm of real effective exchange rate and net foreign assets and use the factors as possible regressors. The rationality for this relies on possible existence of another global factor not well captured by GVAR averages variables.

In order to evaluate the GVAR we must compare it to a more general model. We opt to include others sources of interdependence and structural change in the mean parameters of the model. This general model nests the GVAR structure. We run the Autometrics in two steps.

In the first step the general unrestricted model (GUM) is given by the following equation:

$$
\Delta x_{i, t}=\sum_{h=1}^{q} \theta_{1 h}^{1} V_{h t}^{i}+\sum_{h=1}^{T_{i}} \theta_{2 h}^{1} I S\left(T_{h}\right)+\sum_{h=1}^{T_{i}} \theta_{2 h}^{1} D S\left(T_{h}\right)+\sum_{i=1}^{T_{i}} \theta_{3 h}^{1} D T\left(T_{h}\right)+u_{i}^{1},
$$

where

$$
I S\left(T_{i}\right)=\left\{\begin{array}{ll}
1, & \text { if } t=T_{i}, \\
0, & \text { if } t \neq T_{i} ;
\end{array} \quad D S\left(T_{i}\right)=\left\{\begin{array}{ll}
1, & \text { if } t \geq T_{i}, \\
0, & \text { if } t<T_{i} ;
\end{array} \quad D T\left(T_{i}\right)= \begin{cases}t, & \text { if } t \geq T_{i}, \\
0, & \text { if } t<T_{i}\end{cases}\right.\right.
$$

and $V^{i}=V_{1}^{i}, V_{2}^{i}, \ldots, V_{q}^{i}$ contains all GVAR's country $i$ variables. The superscript denotes the step.

In the second step the general unrestricted model contains the variables of the final model in the first step and broader set of variables:

$$
\begin{aligned}
\Delta x_{i, t}=\sum_{h=1}^{q} \theta_{1 i}^{2} F M_{i t}+\sum_{h=1}^{N} \sum_{j=1}^{k_{i}} \theta_{2 i j}^{2} \Delta x_{h, t-j}+\sum_{h=1}^{N} \sum_{j=1}^{k_{i}} \theta_{3 i j}^{2} \Delta x_{h, t-j}^{*} \\
+\sum_{h=1, h \neq j}^{N} \theta_{4 i j}^{2} e c m_{h, t-1}+\sum_{h=1}^{2 * N} \sum_{j=1}^{k_{i}} \theta_{3 i j}^{2} P C_{h, t-j}+u_{i}^{2},
\end{aligned}
$$

where $F M$ denotes the variables in the final model of step 1 and $P C$ denotes the principal components of all RER and NFA variables, ecm denotes error correction mechanism and the remainder variables were defined previously in the paper.

The GUM of the first step in our exercise contains a total of $\mathrm{TOT}_{1}=T * 3+2 * 6+2+1$ variables. In our application $\mathrm{TOT}_{1}$ equals $75=30 * 3+12+2+1$. The GUM in the second step will contain at least $\mathrm{TOT}_{2}$ variables $(2 *[N+(N-1)]+2 *[N+(N-1)]+$ $(N-1)+2 * N)$. In our example the number of countries is 27 and $\mathrm{TOT}_{2}$ equals 292 . The GUM upper limit will be $292+75=367$. The Autometrics will retain under the null that all coefficients are zero an average of irrelevant regressors given by TOT $=\left(\mathrm{TOT}_{1}+\mathrm{TOT}_{2}\right)$ times the chosen nominal size. If we set the nominal size to 0.0001 (minute), Autometrics will retain 0.0367 irrelevant regressors on average and about 0.367 irrelevant regressors if the nominal size is set to 0.001 (tiny). 
Autometrics allows us to check whether the GVAR approach is a congruent statistical model and a rival model that contains broader information set can encompass the GVAR. If the final model contains only the variables of the traditional approach it is reasonable to conclude that neither GVAR nor the broader GUM are worth taking.

Table 8 provides information on each country final model chosen by Autometrics search algorithm. In some case there is evidence of structural change (e.g. Australia, Greece, Uruguay, Turkey). In these cases, a closer look to other domestic variables can be an alternative. For some countries our evidence suggests that the GVAR can not capture all possible sources of interdependence. For example, in the case of Ireland, a closer link to the dynamics of United Kingdom's real effective exchange was revealed. However the foreign NFA weigthed variable seems to explain the dynamics in United Kingdom and United States cases quite well. These countries have the leading financial centers of the world, and GVAR is probably capturing this interdependence channel. In many countries the final model selected by Autometrics contains the foreign trade weighted variable. This results suggest that GVAR improves of our understanding on the dynamics real exchange rate and net foreign asset. The principal components variables were selected only in some few models. For some countries, the results of Autometrics using minute instead of tiny significance level seems more intuitive (e.g. Brazil or Germany). Spain is the only country that Autometrics results are not easy to rationalize.

\subsection{Discussion, limitations and possible extensions}

The previous discussion on the merits and limitations of the time series and panel approaches is addressed in this section, as well as whether the GVAR model can be a bridge linking both approaches. The time series approaches allow little room to introduce fundamentals because of the sample size available in macroeconomic datasets. The panel approach allows a more flexible structure and the inclusion of a larger group of fundamentals in the analysis. However, this approach must limit heterogeneity to a manageable level. It is not clear to what extent this can lead to distortions, since the main goal is to make assertions on specific units, not to assess the relevance of a group of variables in explaining real exchange rate movements and their average effect. A GVAR model can reconcile the merits of the two approaches, allowing us to map directly the effect of trading partner shocks on a country.

In the same way, it is possible to adapt the decomposition of Gonzalo and Granger (1995) to the GVAR environment. The same can be done for a Beveridge and Nelson decomposition, as shown in the work of Proietti (1997), under a VECM framework. The development of a model for the eurozone is a natural extension of our work. A regional factor can be easily added to the GVAR to map directly the interdependence between countries in the region. To the best of our knowledge, this has not been done before. Although we did not do so, our GVAR model was able to capture a strong interdependence effect among eurozone countries.

Even the IMF approach does not directly tackle the question of interdependence between countries. However, the IMF approach does have the benefit of considering a wide range of fundamentals, and incorporates the role of policy gaps in determining the misalignment.

\section{Final remarks}

In this study, we estimated a global VAR to investigate the interdependence hypothesis among countries in terms of their real effective exchange rates and fundamentals. We were 
Table 8. Summary of Autometrics results.

\begin{tabular}{|c|c|c|c|c|c|c|c|c|c|c|}
\hline \multirow[b]{2}{*}{ Countries } & \multirow{2}{*}{$\begin{array}{l}\text { Type of } \\
\text { search }\end{array}$} & \multicolumn{6}{|c|}{ Variables in the final model } & \multirow{2}{*}{$\begin{array}{c}\text { Evidence of } \\
\text { structural change }\end{array}$} & \multicolumn{2}{|c|}{ Are specification tests good? } \\
\hline & & ECM & RER & Weighted RER & NFA & Weighted NFA & Factors & & At $5 \%$ & At $1 \%$ \\
\hline \multirow[t]{2}{*}{ Australia } & Tiny & 0 & No & No & No & No & No & $D T, D I, D S$ & No & Yes \\
\hline & Minute & 0 & No & No & No & No & No & $D I$ & Yes & Yes \\
\hline \multirow[t]{2}{*}{ Austria } & Tiny & 0 & No & 0 & No & No & No & $D I$ & No & Yes \\
\hline & Minute & 0 & No & No & No & No & No & No & Yes & Yes \\
\hline \multirow[t]{2}{*}{ Belgium } & Tiny & 0 & No & No & No & No & No & No & No & Yes \\
\hline & Minute & 0 & No & No & No & No & No & No & No & Yes \\
\hline \multirow[t]{2}{*}{ Brazil } & Tiny & 0 & No & India, USA & No & No & NFA & $D I$ & Yes & Yes \\
\hline & Minute & 0 & No & No & No & No & No & $D I$ & No & Yes \\
\hline \multirow[t]{2}{*}{ Canada } & Tiny & 0 & No & No & No & 0 & No & No & No & Yes \\
\hline & Minute & No & No & No & No & No & No & No & Yes & Yes \\
\hline \multirow[t]{2}{*}{ China } & Tiny & 0 , Sweden & No & No & Germany & No & NFA & No & Yes & Yes \\
\hline & Minute & 0 & No & No & No & No & No & No & Yes & Yes \\
\hline \multirow[t]{2}{*}{ Colombia } & Tiny & 0 & USA & 0, Mexico & No & No & No & No & Yes & Yes \\
\hline & Minute & 0 & No & No & No & No & No & No & Yes & Yes \\
\hline \multirow{2}{*}{ Denmark } & Tiny & 0 & No & No & No & No & No & No & Yes & Yes \\
\hline & Minute & 0 & No & No & No & No & No & No & Yes & Yes \\
\hline \multirow[t]{2}{*}{ Finland } & Tiny & 0 & No & No & 0 , Ireland & No & No & DT & No & Yes \\
\hline & Minute & 0 & No & No & No & No & No & DT & No & No \\
\hline \multirow[t]{2}{*}{ France } & Tiny & 0 & No & 0 & No & No & NFA & No & Yes & Yes \\
\hline & Minute & 0 & No & No & No & No & No & No & No & Yes \\
\hline \multirow[t]{2}{*}{ Germany } & Tiny & 0, South Africa & No & No & No & No & No & No & Yes & Yes \\
\hline & Minute & 0 & No & No & No & No & No & No & Yes & Yes \\
\hline \multirow{2}{*}{ Greece } & Tiny & No & No & No & No & No & No & $D T, D I, D S$ & No & Yes \\
\hline & Minute & 0 & No & No & No & No & No & No & No & No \\
\hline India & Tiny & 0 & No & No & No & No & No & No & No & Yes \\
\hline & Minute & 0 & No & No & No & No & No & No & No & Yes \\
\hline Ireland & Tiny & 0 & UK & No & No & 0 , Singapore & NFA & No & Yes & Yes \\
\hline & Minute & 0 & UK & 0 & No & 0 & No & No & Yes & Yes \\
\hline Italy & Tiny & 0, South Africa & No & No & No & No & NFA & No & Yes & Yes \\
\hline & Minute & 0 & No & No & No & No & No & No & Yes & Yes \\
\hline Japan & Tiny & 0 & Spain & 0 & No & 0 & No & No & Yes & Yes \\
\hline & Minute & 0 & No & 0 & No & 0 & No & No & No & Yes \\
\hline Mexico & Tiny & 0 & No & 0 & No & 0 & No & No & No & Yes \\
\hline & Minute & 0 & 0 & No & No & No & No & No & No & No \\
\hline Netherlands & Tiny & 0 & No & 0 & No & No & No & No & No & No \\
\hline & Minute & 0 & No & 0 & No & No & No & $D I$ & No & Yes \\
\hline Singapore & Tiny & No & No & No & No & No & No & No & No & Yes \\
\hline & Minute & No & No & No & No & No & No & No & No & Yes \\
\hline Spain & Tiny & 0, Australia & USA & No & No & No & No & No & No & Yes \\
\hline & Minute & 0, Australia, Turkey, Uruguay & USA & Colombia & No & No & No & No & No & Yes \\
\hline Sweden & Tiny & 0 & No & 0 & No & No & No & No & No & Yes \\
\hline & Minute & 0 & No & No & No & No & No & No & No & No \\
\hline UK & Tiny & 0 & No & No & No & 0 & No & No & No & Yes \\
\hline & Minute & 0 & No & No & No & 0 & No & No & No & Yes \\
\hline USA & Tiny & 0 & No & No & No & 0 & No & No & No & Yes \\
\hline & Minute & 0 & No & No & No & No & No & No & Yes & Yes \\
\hline Uruguay & Tiny & 0 & No & No & No & No & No & $D T, D I$ & No & No \\
\hline & Minute & 0 & No & No & No & No & No & DT & No & No \\
\hline South Africa & Tiny & 0 & No & No & No & No & No & No & Yes & Yes \\
\hline & Minute & 0 & No & No & No & No & No & No & Yes & Yes \\
\hline Turkey & Tiny & No & No & No & No & No & No & $D T, D I, D S$ & No & Yes \\
\hline & Minute & No & No & No & No & No & No & $D T, D I, D S$ & No & Yes \\
\hline
\end{tabular}

Notes: "O" refers to own country, $D T$ is break time trend dummy, $D I$ is an impulse indicator, and $D S$ is a step dummy. 
able to find evidence in favor of interdependence in both the short and long run for some countries. In only a few cases in the sample could the null hypothesis of no interdependence not be rejected.

We also discussed the impact that the GVAR may have on exchange rate misalignment estimates. Here, we adapted the Gonzalo and Granger decomposition to a GVAR framework and conducted an empirical exercise to try to explain the relevance of global effects to exchange rate misalignment estimates. Our findings show that the effects are greater for small or developing countries, because they tend to be more affected by global economy conditions.

Our global model was also capable of detecting important linkages between eurozone countries, as expected. The United States and Germany, two leading economies in the world, seem to have an effect on the real exchange rate of other countries. However, their exchange rate misalignment estimates are only marginally affected in terms of magnitude and sign when both models' estimates are compared. The reason for this has to do with the dynamics of their real effective exchange rates, which are almost not affected by others countries' variables.

Finally, possible extensions to our approach include improving on country-specific models by using recent advances in time series model selection to investigate the role of a broader set of domestic variables. We can access not only the statistical significance of external factors but their relative importance in relation to domestic factors.

\section{References}

Ahmad, Y., \& Craighead, W. D. (2011). Temporal aggregation and purchasing power parity persistence. Journal of International Money and Finance, 30(5), 817-830. http://dx.doi.org/10.1016/j.jimonfin.2011.05.008

Alberola, E., Cervero, S. G., Lopez, H., \& Ubide, A. (1999). Global equilibrium exchange rate: Euro, dolar, "ins", "outs," and other major currencies in a panel cointegration framework (IMF Working paper No. 175). International Monetary Fund. https://www.imf.org/en/Publications/WP/Issues/2016/12/30/Global-Equilibrium -Exchange-Rates-Euro-Dollar-Ins-Outs-and-Other-Major-Currencies-in-a-Panel-3369

Bilson, J. F. O. (1979). Recent developments in monetary models of exchange rate determination. Staff Papers (International Monetary Fund), 26(2), 201-223.

http://dx.doi.org/10.2307/3866509

Cline, W. R., \& Williamson, J. (2008). Estimates of the equilibrium exchange rate of the renminbi: Is there a consensus and if not, why not? In M. Goldstein \& N. R. Lardy (Eds.), Debating China's exchange rate policy (pp. 131-168). Peterson Institute for International Economics. https://piie.com/publications/chapters_preview/4150/04iie4150.pdf

Doornik, J. A. (2009). Autometrics. In J. L. Castle \& N. Shephard (Eds.), The methodology and practice of econometrics: A Festschrift in honour of David F. Hendry. Oxford University Press.

Dornbusch, R. (1976). Expectations and exchange rate dynamics. Journal of Political Economy, 84(6), 1161-1176. https://www.jstor.org/stable/1831272

Edwards, S. (1989). Exchange rate misalignment in developing countries. The World Bank Research Observer, 4(1), 3-21. http://documents.worldbank.org/curated/en/737331468739271547/ Exchange-rate-misalignment-in-developing-countries

Edwards, S. (1991). Real exchange rates, devaluation, and adjustment: Exchange rate in developing countries. MIT Press. 
Engle, R. F., \& Granger, C. W. J. (1987). Co-integration and error correction: Representation, estimation, and testing. Econometrica, 55(2), 251-276. http://dx.doi.org/10.2307/1913236

Engle, R. F., Hendry, D. F., \& Richard, J.-F. (1983). Exogeneity. Econometrica, 51(2), 277-304. http://dx.doi.org/10.2307/1911990

Ericsson, N. R., \& Reisman, E. L. (2012). Evaluating a global vector autoregression for forecasting. International Advances in Economic Research, 18(3), 247-258.

http://dx.doi.org/10.1007/s11294-012-9357-0

Faruqee, H. (1995). Long-run determinants of the real exchange rate: A stock-flow perspective. IMF Staff Papers, 42(1), 80-107. http://dx.doi.org/10.2307/3867341

Froot, K. A., \& Rogoff, K. (1995). Perspectives on PPP and long-run real exchange rates. In G. M. Grossman \& K. Rogoff(Eds.), Handbook of internationaleconomics (Vol.3, pp. 1647-1688). North Holland.

Ghysels, E., \& Miller, I. J. (2015). Testing for cointegration with temporally aggregated and mixedfrequency time series. Journal of Time Series Analysis, 36(6), 797-816. http://dx.doi.org/10.1111/jtsa.12129

Gonzalo, J., \& Granger, C. (1995). Estimation of common long-memory components in cointegrated systems. Journal of Business \& Economic Statistics, 13(1), 27-35.

http://dx.doi.org/10.2307/1392518

Hecq, A., Palm, F. C., \& Urbain, J.-P. (2000). Permanent-transitory decomposition in VAR models with cointegration and common cycles. Oxford Bulletin of Economics and Statistics, 62(4), 511-532. http://dx.doi.org/10.1111/1468-0084.00185

Hecq, A., Palm, F. C., \& Urbain, J.-P. (2002). Separation, weak exogeneity, and P-T decomposition in cointegrated VAR systems with common features. Econometric Reviews, 21(3), 273-307. http://dx.doi.org/10.1081/ETC-120015785

Hendry, D. F. (1995). Dynamic econometrics. Oxford University Press.

Hossfeld, O. (2010). Equilibrium real exchange rates and real exchange rate misaligments: Time series vs. panel estimates (Tech. Rep. No. 65). FIW - Forschungsschwerpunkt Internationale Wirtschaft. http://hdl.handle.net/10419/121070 (Working Paper)

IMF - International Monetary Fund. (2013). 2013 pilot external sector report. Washington, DC: International Monetary Fund. https://www.imf.org/en/Publications/Policy-Papers/Issues/ 2016/12/31/2013-Pilot-External-Sector-Report-PP4789

Johansen, S. (1988). Statistical analysis of cointegration vectors. Journal of Economic Dynamics and Control, 12(2-3), 231-254. http://dx.doi.org/10.1016/0165-1889(88)90041-3

Johansen, S. (1995). Identifying restrictions of linear equations with applications to simultaneous equations and cointegration. Journal of Econometrics, 69(1), 111-132. http://dx.doi.org/10.1016/0304-4076(94)01664-L

Kubota, M. (2009). Real exchange rate misaligments (PhD Thesis). University of York, York, North Yorkshire.

Lane, P. R., \& Milesi-Ferretti, G. M. (2007). The external wealth of nations mark II: Revised and extended estimates of foreign assets and liabilities, 1970-2004. Journal of International Economics, 73(2), 223-250. http://dx.doi.org/10.1016/j.jinteco.2007.02.003

Meese, R. A., \& Rogoff, K. (1983). Empirical exchange rate models of the seventies: Do they fit out of sample? Journal of International Economics, 14(1-2), 3-24. http://dx.doi.org/10.1016/0022-1996(83)90017-X

Mussa, M. (1976). The exchange rate, the balance of payments and monetary and fiscal policy under a regime of controlled floating. The Scandinavian Journal of Economics, 78(2), 229-248. http://dx.doi.org/10.2307/3439926 
Pesaran, H. M., Schuermann, T., \& Weiner, S. M. (2004). Modeling regional interdependencies using a global error-correcting macroeconometric model. Journal of Business \& Economic Statistics, 22(2), 129-162. http://dx.doi.org/10.1198/073500104000000019

Proietti, T. (1997). Short-run dynamics in cointegrated systems. Oxford Bulletin of Economics and Statistics, 59(3), 405-422. http://dx.doi.org/10.1111/1468-0084.00073

Rossi, B. (2013). Exchange rate predictability. Journal of Economic Literature, 51(4), 1063-1119. http://dx.doi.org/10.1257/jel.51.4.1063

Shin, Y. (1994). A residual-based test of the null of cointegration against the alternative of no cointegration. Econometric Theory, 10(1), 91-115. http://dx.doi.org/10.1017/S0266466600008240

Stein, J. L. (1995). The fundamental determinants of the real exchange rate of the U.S. dollar relative to other G-7 currencies (IMF Working Paper No. 95/81). International Monetary Fund. https://papers.ssrn.com/sol3/papers.cfm?abstract_id=883229

Taylor, A. M. (2001). Potential pitfalls for the purchasing-power-parity puzzle? Sampling and specification biases in mean-reversion tests of the Law of One Price. Econometrica, 69(2), 473-498. https://www.jstor.org/stable/2692239

Williamson, J. (Ed.). (1994). Estimating equilibrium exchange rates. Peterson Institute for International Economics. 